Pasado y Memoria

ISSN: 2386-4745

Núm. 23, 2021, pp. 210-235

https://doi.org/10.14198/PASADO2021.23.09

Estudios

\title{
Lo que ocurre es que él es ella: Un análisis de las crónicas de Teresa de Escoriaza sobre el desastre de Annual (1921)
}

\section{Lo que ocurre es que él es ella: An analysis of the Teresa de Escoriaza's reports of the Annual disaster (1921)}

\author{
María Gajate Bajo \\ Universidad de Salamanca, España \\ mariagajate@usal.es \\ https://orcid.org/0000-0003-2459-3712 204
}

Recibido: 22/01/2021

Aceptado: 22/03/2021

Cómo citar este artículo: GAJATE BAJO, María (2021). Lo que ocurre es que él es ella: Un análisis del las crónicas de Teresa de Escoriaza sobre el desastre de Annual (1921). Pasado y Memoria. Revista de Historia Contemporánea, (23), pp. 210-235, https:// doi.org/10.14198/PASADO2021.23.09

\section{Resumen}

A raíz del desplome de la Comandancia General de Melilla (julio de 1921), el Ejército de África, encabezado por la Legión, asumió la tarea de recuperar el territorio perdido. Las guerras coloniales entre España y Marruecos durante las primeras décadas del siglo XX acapararon la atención de muchos reporteros, especialmente, el episodio conocido como Desastre de Annual. Tal fue el caso de Teresa de Escoriaza (1891-1968), una profesional polifacética, capaz de hacerse un hueco en el panorama periodístico de aquel entonces. Teresa llegaría al Protectorado hispano-francés como enviada del rotativo izquierdista La Libertad. Mostrando su plena identificación con el patriotismo castrense, envío un total de dieciocho crónicas a su periódico, que se publicaron entre los días 3 y 27 de septiembre de ese mismo año. El objetivo del presente trabajo consiste en analizar minuciosamente estas crónicas y reflexionar sobre la relación de Teresa con la oficialidad africanista y su sintonía con el público en general y su sintonía con el público en general. 
Palabras clave: España; Marruecos; Teresa de Escoriaza; Desastre de Annual; Periodismo de Guerra; La Libertad.

\begin{abstract}
After the collapse of the Melilla Headquarters (July 1921), the Army of Africa led by the Legion assumed the task of recovering the lost territories. The colonial wars between Spain and Morocco, during the first decades of the twentieth century, caught the attention of numerous columnists and, above all the «Disaster of Annual». This was the case of Teresa de Escoriaza (1891-1968), a multitalented woman, capable of making a place for herself in the journalistic panorama of the time. Teresa arrived at the Spanish-French Protectorate as correspondent for the leftist newspaper La Libertad. Showing full identification with military patriotism, she sent back eighteen chronicles which were published between 3-27 September. The aim of this paper is to closely analyse those reports and identify the relationship between Teresa de Escoriaza and the Africanist caste with public opinion.
\end{abstract}

Keywords: Spain; Morocco; Teresa de Escoriaza; Disaster of Annual; War Journalism; La Libertad.

\title{
Introducción
}

Teresa de Escoriaza no es excesivamente conocida en la actualidad, pese al encanto que irradia su figura y al carácter pionero que exhibió en varios momentos de su vida: maestra, traductora, activista, etc. Pero, sobre todo, periodista. En una época en la que el oficio de corresponsal de guerra era (casi) exclusivamente desempeñado por hombres, ella supo ganarse la vida con su pluma, a la vez sobria y directa, haciéndose un hueco en el panorama informativo español. Es más, gozó de enorme popularidad, lo que le sirvió para trabajar como locutora en Radio Ibérica desde 1924, y ocupó un lugar destacado en la historia del feminismo patrio.

Al conocerse en la península el desastre de Annual (Marruecos), provocado por una huida en desbandada de miles de soldados españoles despavoridos ${ }^{1}$,

1. Entre los principales testimonios de este significativo episodio destacó el del periodista Gómez Hidalgo, muy popular gracias a sus incisivos comentarios sobre la gestión del Protectorado (Gómez Hidalgo, 1921). El médico Ruíz Albéniz prefirió, por su parte, cargar las tintas contra el Comandante General de Melilla, el impulsivo general Fernández Silvestre (Ruiz, 1922). El diputado y periodista Eduardo Ortega y Gasset viajó a Melilla y recogió el testimonio de Bernabé Nieto, un joven soldado madrileño (Ortega, 1922). Augusto Vivero y el socialista Indalecio Prieto se convirtieron en feroces denunciantes de las corruptelas practicadas en el Rif (Vivero, 1922; Prieto, 2001). Al teniente coronel Eduardo Pérez Ortiz, siempre grandilocuente y dispuesto a verter juicios exculpatorios, debemos finalmente agradecerle uno de los principales relatos -junto con el del sargento 
Escoriaza no lo pensó dos veces: se trasladó a Melilla para cubrir la campaña posterior de reocupación del Rif ${ }^{2}$. La magnitud de esta tragedia fue colosal y, en términos políticos, marcó un punto de no retorno para el agonizante régimen de la Restauración. Además, para la moral del ejército, el colapso de la Comandancia General de Melilla resultó equiparable a los desastres de Santiago y Cavite para la marina en 1898 (Macías, 2019: 59-99). El resultado del viaje de Escoriaza fueron dieciocho crónicas, publicadas a lo largo de septiembre de 1921, bajo el título «Del dolor de la guerra». El éxito cosechado por Escoriaza animó a que pronto se reeditaran estos artículos en forma de libro, prologado por Antonio de Zozoya ${ }^{3}$. Se constató también la buena acogida de la obra cuando a Teresa le dedicaron un banquete-homenaje en Hotel Ritz de Madrid, a finales de noviembre. Así lo reseñaba uno de sus colegas:

«No hay más que un periodista, uno de tantos, al que su director envió a Marruecos y que allí cumplió con sus deberes lo menos mal que pudo y que supo. Lo que ocurre es que él es ella. Que no se trata de un hombre, sino de una mujer, y que como aquí, en España, es la costumbre que las mujeres no compitan con los hombres, ha llamado la atención del público» ${ }^{4}$.

Teresa sobresalía, incluso en los círculos castrenses. De hecho, fue elegida para presidir un acto en honor, nada menos, que de Santiago González Tablas, el jefe de los Regulares de Ceuta ${ }^{5}$. En conjunto, sin embargo, la producción literaria y periodística de Teresa resultó menos voluminosa que la de Carmen de Burgos, la otra gran corresponsal española en África. Más conocida como Colombine,

Basallo (1924) - sobre el cautiverio sufrido por los supervivientes del ataque rifeño (Pérez, 1923).

2. La zona norte del Marruecos español, según se había acordado en el Convenio hispano-francés de 1912, contaba con una superficie de 22.790 kilómetros cuadrados, que representaban una mínima concesión ante los 415.000 kilómetros cuadrados de protectorado galo. Se trataba de un terreno montañoso, sobre todo si pensamos en la región del Rif (la que rodea Melilla), con un régimen hidrográfico pobre y una climatología poco propicia. La población era de unos 750.000 habitantes, con predominio étnico de los beréberes.

3. Zozoya, compañero de redacción, describía a Teresa como «ágil, nerviosa, varonil [...] ¿Es una iluminada, una heroína, una hembra desdeñosa del sexo o una propagandista de su exaltación regeneradora y romántica?». Del dolor de la guerra, editado por Pueyo, salió a la venta por dos pesetas y fue muy publicitado en las páginas de La Libertad entre octubre de 1921 y hasta el verano siguiente. Las crónicas de Escoriaza no experimentaron modificaciones en su contenido ni recortes, pero sí se alteró su ordenación original, quizás, para dosificar su carga emocional.

4. ANÓNIMO, «Consagración de una escritora. El banquete a Teresa de Escoriaza», La Libertad, 21 de noviembre de 1921, p. 4.

5. ANÓNIMO, «Informes de Madrid. Banquete a González Tablas. Honrando a un héroe», La Libertad, 03 de noviembre de 1921, p. 1. 
había sido la única cronista de notoriedad en la campaña hispano-marroquí previa, la del año 1909 (Núñez, 1991; Zapata-Calle, 2001).

El tono de Escoriaza a la altura de 1921, no obstante, fue mucho más áspero y ágil que el de Colombine a la hora de conjugar información con reflexión. El análisis de los escritos de esta intrépida mujer, por su riqueza de matices, por su manifiesta adhesión al proyecto colonial español y por la inmediatez con los acontecimientos históricos, está plenamente justificado y sirve para enriquecer las investigaciones a propósito de la guerra del Rif y su impacto público. Cabe lógicamente preguntarse cuáles fueron los intereses de Teresa de Escoriaza en Marruecos y qué razones explican un discurso tan duro. ¿Qué imagen divulgó del Protectorado? ¿Qué rol asumió como periodista? ¿Respaldó la campaña de desquite de Antonio Maura y la labor de los africanistas? En las páginas que siguen se intentará responder a estas cuestiones, anticipamos ya, para que lector vaya conociendo a la reportera, que Escoriaza siempre se mostró pendiente de lo que ocurría en Melilla y más aún del bienestar de las tropas. A Teresa le inquietó el sufrimiento compartido por los combatientes y, sobre todo, las secuelas de la contienda.

Teresa de Escoriaza, pionera del periodismo en España. Breve estado de la cuestión

Aunque el propósito de este trabajo no consista en biografiar a Teresa de Escoriaza, conviene efectuar un ligerísimo esbozo de su trayectoria vital para entender así mejor ese vanguardismo que tanto la definió. Nacida en San Sebastián (1891), Teresa se educó en Madrid, Burdeos y Liverpool. Residió además en Estados Unidos, donde ejerció como profesora de idiomas entre 1917 y 1921, y entretanto colaboró con el periódico La Libertad, que dirigía Luis de Oteyza. Fue este diario de inspiración albista el que costeó su traslado a Marruecos a finales de agosto de 1921 para cubrir los sucesos posteriores al desastre de Annual (también viajarían en distintos momentos Eduardo Ortega y Gasset, Ezequiel Endériz, Francisco Hernández Mir y Antonio de Lezama). La redacción pretendía con semejante decisión amplificar la visión femenina de la conflagración hispano-marroquí, pero manteniendo a la reportera siempre alejada del frente: que visitara hospitales, campamentos y diese cuenta del drama ocasionado por la guerra. Le asignaron, por tanto, un papel secundario y revelador de cierta actitud condescendiente entre sus colegas, pero al que Escoriaza no se subordinó.

Catapultada a la fama tras su paso por África, Teresa comenzó a figurar como una integrante más de la redacción a partir de 1922. También colaboró con el vespertino Informaciones y publicó una novela junto con varias 
traducciones (Palenque, 2006: 360). En 1929, la inquieta periodista regresó a Nueva York y, cinco años después, cesaron sus colaboraciones con La Libertad. Coincidiendo con el desarrollo de la Guerra Civil, en 1938, adquirió la nacionalidad norteamericana, aunque regresó a su tierra natal al jubilarse en 1958. Aquí falleció diez años más tarde.

Como ya se ha enunciado, la labor periodística de Teresa de Escoriaza, en buena parte desarrollada desde el extranjero, ha merecido muy escasa atención tanto desde la perspectiva filológica como desde la historiográfica. Probablemente sea la profesora Marta Palenque (2006: 365-373) quien haya efectuado un análisis más pormenorizado de su obra, poniendo de relieve su doble dimensión como escritora y maestra en el extranjero. Así, Palenque describe a una mujer culta, muy ambiciosa y valiente, de juicios agudos y tono desenfadado. Puntualiza, por otro lado, que su envío a Marruecos constituyó todo un golpe de efecto por parte de La Libertad. No sería el único, pues cabe recordar que, al año siguiente, en 1922, Oteyza añadiría a su currículo una excepcional entrevista con el líder rifeño Abd-el-Krim ${ }^{6}$.

En menor medida, también Manuela Marín, una excelente conocedora de la historia del Protectorado y de los contactos hispano-marroquíes, reparó en la obra de Teresa cuando realizó un breve estudio sobre algunas reporteras de guerra a comienzos del siglo XX. Marín entiende la campaña militar del Rif como un escenario idílico para lograr una mayor visibilidad femenina y ha destacado de Escoriaza su atracción por los aspectos más duros del conflicto a la par que cierto empeño, de lo más curioso en una coyuntura donde todos clamaban venganza, por empatizar con el enemigo (Marín, 2013: 29-30).

Para ir finalizando este sucinto repaso, subrayemos que, en un monumental estudio sobre el trabajo de los corresponsales de prensa en África durante el primer cuarto de la pasada centuria, el investigador Antonio García Palomares ha incidido en que Escoriaza siempre se esmeró en sus crónicas por trascender a lo que, en apariencia, eran meras anécdotas. Desde un enfoque más técnico, este autor recalca la mezcla intencionada de géneros en sus escritos, el reportaje y la crónica, y el abuso en el empleo de la primera persona con la evidente intención de mostrar la cercanía del dolor (García, 2014: 264-265). Noemí López Alcón, por su parte, defendió recientemente una tesis doctoral sobre la narrativa breve y las crónicas de guerra hasta 1945. A propósito de Teresa

6. Con el título de Abd-el-Krim y los prisioneros, este trabajo se ha reeditado varias veces desde 1924 y fue prologado, en el año 2000, por M. ${ }^{a}$ Rosa de Madariaga. Remitimos a la bibliografía para su consulta, así como también recogemos el estudio de Rubio Campaña (2015) sobre la andadura de este insigne periodista. 
de Escoriaza, esta especialista hace hincapié en su compromiso y sensibilidad hacia el sufrimiento femenino (López, 2015: 11 y 161).

Precisamente, el trágico desastre de Annual -trágico para los españoles ${ }^{7}$ le ofreció a Escoriaza la ocasión ideal para dar rienda suelta a esa sensibilidad y marcado compromiso con la sociedad de su época.

\section{El desastre de Annual, un filón para los cronistas de guerra.}

\section{Los hechos: génesis y consecuencias inmediatas del desastre de Annual}

En la madrugada del 21 de julio de 1921 se inició el famoso desastre de Annual ${ }^{8}$. En este enclave, situado en pleno corazón del Rif y que hacía las veces de punta de lanza del avance español hacia la bahía de Alhucemas ${ }^{9}$, las tropas peninsulares iniciaron una desesperada huida que culminó con el casi completo derrumbe de la zona oriental del Protectorado. El harca rifeña -grupos irregulares de combatientes marroquíes- había iniciado su hostigamiento sobre Annual el día 21 de julio. Repetía de este modo la jugada efectuada desde mediados de junio sobre la posición de Igueriben que, a tan solo seis kilómetros, fue sitiada y devorada ante la mirada impotente y atónita de los destacamentos más próximos (Casado, 2007). Conocidas las complicaciones que suponía una resistencia prolongada en Annual, el abandono pareció la mejor opción a seguir. Al menos, así se determinó en una doble junta de jefes, presidida por el

7. Mientras que en España el cáncer marroquí (expresión frecuentemente utilizada por la prensa) actuó como aglutinante de todos los descontentos hacia el sistema político, Annual trajo consigo en el Protectorado el inicio del apogeo de Abd-el-Krim, el gran caudillo rifeño, y la aparición de un primer referente «nacional» en su historia (Woolman, 1971; Pennell, 2001; Madariaga, 2009).

8. Entre las principales investigaciones sobre esta batalla, el trabajo de Manu Leguineche (1996) destaca por su carácter ameno y por estar aderezado con oportunas entrevistas. Otro tanto puede decirse del ensayo de Juan Pando (1999), didáctico y repleto de apuntes biográficos sobre los militares implicados en esta historia. El investigador Pablo La Porte concedió en sus estudios $(1997 ; 2001)$ un particular protagonismo al faccionalismo militar. También escarbó en las repercusiones nacionales e internacionales de la derrota. Fernando Caballero Echevarría, en cambio, escudriñó el origen del derrumbamiento de la Comandancia de Melilla desde un enfoque comparado con el modelo de penetración francés. Su estudio, fundamentado en un amplio recurso a fuentes militares españolas, galas y marroquíes, ha apuntalado el consabido listado de errores que confluyeron en Annual y enfatizado la responsabilidad, habitualmente diluida, del general Navarro en la retirada (Caballero, 2013). Para terminar, el exhaustivo estudio del diplomático Julio Albi de la Cuesta bucea en la maraña de datos y declaraciones recopilados por el juez instructor Picasso para retratar a un ejército que arrastraba considerables problemas estructurales y a un país desquiciado y asolado por la carencia de estabilidad y paz (Albi, 2014).

9. Alhucemas, la «guarida» de Abd-el-Krim, figuraba como gran objetivo estratégico de las operaciones militares españolas desde el remoto 1909 (Díez, 2019). 
comandante general de Melilla, el general Fernández Silvestre ${ }^{10}$. Sin embargo, resultó absurdo no informar a los oficiales sobre cómo habían de proceder. La evacuación se convirtió en una desbandada presidida por el pánico. Silvestre murió sin saberse exactamente cómo (Gómez Martínez, 2009). Los que no cayeron agotados en la huida o fueron hechos cautivos, llegaron a Ben Tieb, pasaron por Dar Drius, Batel, Tistutín y, por último, se refugiaron Monte Arruit. Aquí resistieron hasta el 9 de agosto, cuando la sed, capaz de enloquecer, así como la falta de víveres, municiones y medicinas, les obligó a rendirse (Moga, 2004: 37-43). Se habían echado por tierra todos los avances logrados por España en la región desde 1909.

En semejante atmósfera de caos, no se pudo precisar el número de fallecidos peninsulares y todavía hoy las cifras que baraja la historiografía bailan entre 8.000 y 12.000 personas (Balfour, 2002: 146; Prieto, 1990: 144). El gobierno del conservador Allendesalazar implantó, desde el día 25, la censura -un infructuoso intento de poner la venda antes de que aflorara la herida-, pero la crisis política resultó inevitable. El ejecutivo, desbordado tras la masacre de Monte Arruit ${ }^{11}$, se vio forzado a dimitir y fue reemplazado por otro gabinete bajo el mando de Antonio Maura (Terreros, 2013: 256). Una derrota con tal mortandad, a manos de unos indígenas «por civilizar» dejó el prestigio militar y también político de España por los suelos (Serna, 2001: 227-228). El sueño colonial, que había despertado bastante entusiasmo a finales de la centuria anterior, se hizo añicos al cuestionarse qué llevó a un país vacilante y sin recursos a formar un protectorado -sancionado por tratados que implicaron una lucha con uñas y dientes- en una región tan conflictiva y mísera (Martínez Carreras, 2000; Ramiro, 2001: 17).

Sea como fuere, en un contexto de efervescencia imperialista, España no podía cruzarse de brazos ante la urgente necesidad de defender Melilla y de salvaguardar su imagen internacional, así que tan solo siete semanas después de la caída de Annual comenzó la contraofensiva. La Legión, con apenas un año de vida, acudió en auxilio de los melillenses al tiempo que el espíritu de venganza sacudió al ejército colonial, y sobre todo a sus oficiales, durante los años que siguieron al descalabro de $1921^{12}$. De inmediato se abandonó la vieja estrategia de control territorial mediante blocaos ${ }^{13}$, potenciándose en su lugar las unidades móviles sostenidas a través del pillaje y la extorsión. Las tropas recuperaron Nador el día 17 de septiembre; Zeluán, el 14 de octubre; y Monte Arruit, diez días más tarde. Les siguieron las cábilas de Ulad Settut, Quebdana y el 10 de enero de 1922 los españoles llegaron a Dar Drius, donde concluyó la primera fase de la «reconquista». Antonio Maura -y Berenguer desde la Alta Comisaría de Tetuán- se había esmerado para salvar las apariencias ante 
Europa; gracias a la veloz reanudación de las operaciones había reparado el daño, aunque de forma parcial y con un alto precio ${ }^{14}$.

\section{La hipótesis de partida: ¿el periodismo al servicio de la Patria?}

Ante la gravedad de lo sucedido en el Norte de Marruecos, parece lícito plantearse hasta cuándo fue efectivo ese ardoroso deseo de revancha, del mismo modo que no está de más interrogarse sobre el protagonismo asumido por los reporteros a la hora de espolear a la opinión pública para que respaldase el avance de las tropas. Planteémoslo de otra forma: ¿se confundieron periodismo y patriotismo? ¿Lo hizo Escoriaza? Creemos que sí, en efecto, e intentaremos demostrarlo seguidamente. Empecemos respondiendo a la primera cuestión.

Periodismo y patriotismo (en su versión más militarista y ruidosa) se fundieron en los meses que siguieron a la escabechina de Annual porque la propaganda y la guerra iban -todavía van- de la mano: con la primera se persuade y manipula a las masas. Después del previsible y monumental sobresalto, la opinión aceptó de buen grado el envío masivo y urgente de tropas a África (Marichalar, 1923: 483-484)15. Incluso pudiera afirmarse que Maura -cuyo pulso no había temblado cuando movilizó a los reservistas en el lejano 1909disfrutó de mayores apoyos que cualquier otro gabinete del reinado de Alfonso XIII porque varias razones se conjugaron para explicar esa respuesta ciudadana. De hecho, la investigación histórica ha puesto el acento en el comportamiento de las fuerzas políticas, capaces de ofrecer una imagen cohesionada ${ }^{16}$; en el respaldo de la Iglesia Católica, de las corporaciones municipales e infinidad de particulares, manifiesto en multitud de actos caritativos más o menos espon-

14. Las escisiones gubernamentales afloraron coincidiendo con la celebración de la Conferencia de Pizarra, en febrero de 1922. Maura era proclive a una ocupación militar muy parcial, pero la situación del ejército era de extrema fragilidad. El presidente pretendía satisfacer a los africanistas, especialmente a Berenguer, mediante un desembarco en Alhucemas, a modo de sucedáneo de una ofensiva generalizada, mientras que el ministro de Estado, González Hontoria, defendía el aislamiento del Rif central y una acción negociadora en la región de Yebala. Estas discrepancias aceleraron la crisis del ejecutivo, que cayó un mes después.

15. En el ámbito historiográfico, Ángel Comalada (1985: 15) explicaba el consenso imperante en la segunda mitad del año 1921 apelando a «la vaguedad informativa y los complejos rasgos de psicología colectiva que aquí [...] suelen operar en su lugar en el plano social, y que, cegados los auténticos cauces de participación ciudadana, afloran en los mil canales del rumor, la exageración, la insidia; las reducciones frustradas de la política en las tertulias de café y los corrillos callejeros».

16. Reiteradamente se ha llamado la atención sobre la relativa pasividad de la CNT y del PSOE en aquellos instantes (el PCE, recién fundado, tenía muy escasa entidad y operatividad), si bien el socialismo acabaría encabezando la campaña en pro de la depuración de responsabilidades (Madariaga, 2005: 169-197). 
táneos; en la marcha ordenada de los «cuotas» a África; y, para terminar, en el papel asumido por la prensa, prudente y abnegada (La Porte, 1997: 287).

En conjunto, los gritos de revancha resultaron mucho más habituales para encender a la población que cualquier apelación a los imperativos geográfico e histórico o que las exhibiciones de nostalgia imperial. Por descontado, también infinitamente más frecuentes que las llamadas al abandono (Rubio, 2005: 106153; García, 2014: 239-289). El país clamaba revancha porque la opinión se encontraba afectada por lo que, desde la teoría de la Comunicación Política y la psicología de las masas, se conoce como el síndrome Rally Round the Flag (Groeling; Baum, 2008: 1065-1085; Baum; Potter, 2008: 39-65). Un « ¡cierren filas!» en grado extremo, que hoy en día es utilizado para comprender la relación entre las crisis diplomáticas y la conducta pública. Por este motivo resultó tan extraña y calurosa la acogida dispensada por el país al gobierno de Antonio Maura tras la masacre en Monte Arruit. Muy incisivo, Jesús Pabón (1952: 238) escribió: «En un primer tiempo, no hay cuestión. En todas partes, Annual parece haber producido una unidad de entusiasmo y pareceres [...] apiña, por raro caso, a los españoles en torno al poder público, con edificante unanimidad de entusiasmos y colaboraciones».

Este « ¡cierren filas!», útil para reforzar al ejecutivo ante un desafío excepcional, se explicó por el natural empeño de la opinión pública, arrastrada por el pánico, en contemplar al presidente como encarnación de la unidad nacional ${ }^{17}$. Además, fue la consecuencia de la ausencia inicial de críticas desde la oposición política. Ambos elementos redundaron, por consiguiente, en un incremento de la popularidad del gobierno maurista (Terreros, 2013). Annual no solo significó el derrumbe del ejército de África; sino que la dramática muerte de aquellos soldados colocó al país también al borde del precipicio. De ahí la incongruencia: la parálisis de la opinión no fue un indicador de conformidad, sino de terror. Debe entenderse que la magnitud de la catástrofe de julio de 1921 fue muy superior a la de 1909; afectó a más capas sociales; y despertó muy elevados niveles de solidaridad. Por todas estas razones, la justificación de la «reconquista» resultó para el gobierno, la diplomacia y, por supuesto, los periodistas una labor más sencilla. Además, mientras que en 1909 el general Pintos actuaba en un territorio ajeno a la soberanía española, doce años después Silvestre se estaba moviendo en una región que sí había sido adjudicada a España.

17. El concepto se ha utilizado ampliamente en el ámbito de las relaciones internacionales. Sus estudiosos han subrayado, no obstante, la utilidad de otra expresión inseparable del rally, la de "guerra de distracción». Con ella se denuncia el oportunismo de algunos presidentes, capaces de generar crisis internacionales para aferrarse al cargo. 
No obstante, semejante unanimidad de pareceres sería momentánea. Baste con señalar que algunos de los intelectuales más prestigiosos de la España alfonsina no tardaron en apercibirse de las difíciles circunstancias en que se estaba desarrollando la campaña del desquite. Miguel de Unamuno aludió a una «botaratada» y mostró su repulsa ante el empleo de agentes químicos en el Rif ${ }^{18}$. Además, denunció la incomprensión generada por toda la gestión del Protectorado ${ }^{19}$. Desde el polo opuesto, otro pensador vasco, Ramiro de Maeztu, se preguntaría si se podía permanecer en Marruecos «eficazmente sin una opinión pública que sostenga a las tropas $[\ldots]$ ¿Por qué la ineficacia militar? ¿Por qué la política internacional a espaldas del país? ¿Por qué han de ser exclusivamente las responsabilidades para militares de poca graduación? $»^{20}$. Denunciaba, se colige de sus comentarios, la actuación entre bambalinas de la diplomacia y la escasa diligencia mostrada en la depuración de responsabilidades de índole política.

La conclusión es simple: al margen de partidismos, la censura, el hermetismo diplomático y el oportunismo de los políticos empezaban a resultar insultantes. ¿Por qué nadie respondía honestamente ante la opinión? Con el transcurso de las semanas y el comprensible desgaste generado por la contienda, renació el sentimiento de impotencia. Al finalizar el año 1921 comenzaron a pasarle factura al gobierno asuntos como el de las responsabilidades, un inoportuno proyecto de recompensas militares y el espinoso tema del rescate de prisioneros. Por último, pero no menos importante, fue entonces, ante la proximidad de las festividades navideñas, cuando más se recordó a los soldados ausentes (Gajate, 2012: 425-428). Ese « ¡cierren filas!», insistamos en ello, tenía sus días contados. Aunque definió, y es lo que nos interesa tener muy presente en adelante, el contexto en el que escribió Escoriaza.

\section{¿Una mujer en el frente? Análisis de las crónicas de Escoriaza en La Libertad}

El 22 de julio de 1921, los españoles amanecían con la noticia del traslado a la catedral de Burgos de los restos del Cid. La primera plana de todos los periódicos de gran tirada estaba protagonizada por la familia real, que había presidido el acto para luego regresar de veraneo a San Sebastián. Excepcionalmente, algunos diarios se hacían eco vagamente de las dificultades que atravesaban los hombres de Silvestre en el sector de Annual. En días sucesivos, la estrategia de minimización de daños emprendida por el Gobierno de Maura (y La Cierva) pudiera haberse hundido, quizás, ante la llegada de los primeros corresponsales al teatro de la guerra. Sin embargo, ya sabemos que no lo hizo de inmediato. Fue en esta dificilísima coyuntura cuando Teresa de Escoriaza desembarcó, consternada y confusa como tantos otros periodistas, en una plaza amenazada. 
Siempre con la mirada puesta en los atacantes rifeños, apostados en el monte Gurugú.

A principios del siglo XX, en España, eran muy pocas las jóvenes acomodadas que se decantaban por las profesiones liberales. En el ámbito periodístico sobresalieron Carmen de Burgos, contratada por Heraldo para dar cuenta de las labores de la Cruz Roja de Melilla -teóricamente desde Málaga, pero no se plegó a ello- y, aunque mucho más desconocida, Margarita Ruiz de Lihori (Marín, 2013). Habitualmente emplearon seudónimos o añadieron un aristocratizante «de» al apellido de su esposo. Teresa, sin ir más lejos y para evitar burlas, se había escudado en muchas ocasiones tras «Félix de Haro». Con o sin seudónimo, Teresa de Escoriaza rompió moldes a lo largo de su vida. Viajó siempre que pudo, aprendió idiomas, nunca se casó ni mostró el más mínimo interés por la vida doméstica. Arremetió, y quizás sorprenda, contra el afamado Lyceum Club que impulsaba María de Maeztu -«proyecto femenil con apariencias de feminista ${ }^{21}-\mathrm{y}$ renegó, exhibiendo su fuerte personalidad, de toda imitación de roles masculinos por parte de la mujer.

La clave de bóveda de su discurso a propósito de la guerra del Rif siempre fue el dolor o, si se prefiere, la denuncia de los sacrificios que imponía la patria. ¿Significa esto que Teresa no equiparó periodismo y patriotismo? ¿En qué medida alentó esta reportera el espíritu de revancha entre la opinión pública? Se impone en primer término, y por aquello de que quien paga manda, conocer mejor al periódico La Libertad. Muy cercano al credo socialista, La Libertad nació en diciembre de 1919, fruto de una crisis (la huelga de parte de los trabajadores) en el seno de El Liberal (Seoane y Saiz, 1996: 26) ${ }^{22}$. De carácter bastante popular y entretenido, La Libertad tardó poco en gozar del favor del público, pudiendo presumir de una tirada que ascendía a los 92.000 ejemplares en junio de 1920 (Fuentes; Fernández, 1997: 199). Andando el tiempo, esta publicación se mostró implacable con el dictador Primo de Rivera, se escoró más aún hacia la izquierda durante el primer bienio republicano y pudo sobrevivir hasta el final de la Guerra Civil -se habían publicado casi un total de 6.000 ejemplares-.

21. ESCORIAZA, Teresa de, «Crónica. El verdadero club de las mujeres», La Libertad, 12 de enero de 1926, p. 1; y «Crónica. ¡Abajo todos los clubs!», La Libertad, 14 de enero de 1927, p. 1.

22. Por norma, cada número de La Libertad contaba con ocho páginas y presentaba secciones y algunas columnas fijas, tales como «La política del día», «Los poetas del día», "Nuestros colaboradores» o «La bolsa de Madrid». Incluía, además, infinidad de editoriales, noticias sobre la vida parlamentaria, entretenimiento taurino y cinematográfico, un creciente espacio para los anunciantes y, por descontado, fotografías y viñetas. 
No existe la certeza de que Teresa de Escoriaza fuese una de las promotoras de la ruptura con El Liberal ${ }^{23}$, pero sí es posible afirmar que pronto supo ganarse el afecto de los lectores y labrarse una imagen prestigiosa, haciendo gala de su actitud comprometida con la actualidad y asistiendo a multitud de banquetes y actos de homenaje. Durante la guerra del Rif, mientras que los periodistas masculinos se volcaron en la descripción de acciones de combate y en el recuento de bajas, a Escoriaza se le encomendó una labor más discreta y acorde con el tradicional papel de la mujer. En Marruecos, su tarea consistiría en la atender y cuidar de los soldados enfermos, sirviendo de intermediaria con sus parientes peninsulares, con sus novias y calmando los ánimos. Debía comprobar qué comían, si dormían convenientemente, aconsejarles lecturas, etc. Ese era el rol asignado a esta periodista: debía hacer las veces de madre de la tropa. Y Teresa así lo hizo, pero no le bastó con recorrer los hospitales y los campamentos de retaguardia, sino que le sedujo la crueldad de la guerra. Se excedió de sus obligaciones al visitar algún que otro blocao y fue testigo de varias escaramuzas, obviando las limitaciones impuestas por su condición femenina.

Sin duda, la sorprendente libertad de movimientos de esta enérgica corresponsal se sustentaba en la buena acogida de sus crónicas, particularmente, entre mujeres. La Libertad era un periódico joven y muy consciente de que las empresas periodísticas más sólidas eran aquéllas con una visión más pragmática del negocio. En este sentido, sabemos que Teresa de Escoriaza dirigía sus escritos a las madres, hermanas y novias de combatientes: «A vosotras, desconocidas amigas mías, es transmitido. Lo recibí con la angustia que lo hubierais recibido vosotras. Va así, como si a vosotras mismas hubiera sido hecho» ${ }^{24}$. Un mensaje directo, diseñado para la satisfacción de un público concreto y con algunos ejes temáticos bien definidos ${ }^{25}$. Se impone, en segundo término y conocidas las pretensiones de La Libertad, analizar estos ejes.

\section{La Comandancia General de Melilla en el punto de mira de los españoles}

A la periodista vasca le importaban los hechos y, como buena reportera de guerra, supo dar oportuna cuenta de los desplazamientos del ejército

23. Escoriaza participa en esta publicación desde el primer número, pero hay que esperar hasta 1922 para verla nombrada como redactora en la primera plana.

24. ESCORIAZA, Teresa de, «Del dolor de la guerra. Morituri te salutan», La Libertad, 8 de septiembre de 1921, p. 1.

25. Aunque hacia 1930, el analfabetismo afectaba a más de la tercera parte de los españoles y los periódicos eran un lujo para muchísimos bolsillos, su difusión considerable debido a la extendida costumbre de la lectura pública. 
expedicionario español en África, pero sin necesidad de precisar el número de movilizados, los convalecientes y fallecidos, las piezas de artillería empleadas, etc. Le importaban mucho más las emociones.

En las crónicas de Teresa de Escoriaza se respira un ambiente opresivo y profundamente triste. La imagen que divulga del Protectorado, de su zona oriental, es la de un territorio que requiere de una acción urgente. Melilla, secular plaza española en África que permanecía sitiada desde finales de julio, sirve como el mejor ejemplo de esta atmósfera. Aquí, pese sus similitudes con cualquier alegre y soleada ciudad andaluza, la ansiedad pesa como una losa: «Las alegres casas, que convidan al bienestar, parecen desiertas» ${ }^{26}$. Es cierto que se mantiene la actividad comercial y que no se han interrumpido las comunicaciones, pero como subraya la escritora a continuación: «Notamos la carencia de ese movimiento del salir a luchar y regresar del combate. Notamos la depresión y el agobio producidos por la inactividad forzosa». A tenor de estas palabras, la fórmula del protectorado civil carecía de validez a juicio de Teresa. Al contrario, esta descripción servía como clara llamada a la guerra, a la necesidad de lograr un sueño tranquilo y sin paqueos ${ }^{27}$. El aislamiento de la Comandancia le resultaba asfixiante y la espera de los refuerzos, insufrible. El eterno dilema sobre la conveniencia de un régimen civil -una idea que se venía madurando desde el término de la Gran Guerra- o militar había llegado a su fin (Villanova, 2005). Con los rifeños no valían las medias tintas (el estereotipo del salvajismo marroquí), ya no cabían las contemplaciones ${ }^{28}$.

La reconquista del terreno perdido, lejos de suponer un alivio, despertó en Teresa de Escoriaza cierto sentimiento de amargura. Así se evidenciaba -saltamos unas semanas- durante su recorrido por la posición de Nador. Comentaba entonces la reportera: «Cuánta ruina, cuánta desolación, cuánta tristeza en lo que fue como una ciudad de juguete, tan bonita y cuidada [...] Piedra a piedra, ladrillo a ladrillo, desde el pavimento a los muros, todo ha sido roto ${ }^{29}$. Se puede reconstruir el cuartel, la iglesia, etc., pero las víctimas nunca hallarán reparación y particularmente impactante para Escoriaza será la imagen de una

26. ESCORIZA, Teresa de, «Del dolor de la guerra», La Libertad, 3 de septiembre de 1921, p. 1.

27. Actividad de los francotiradores rifeños o «pacos», con excelente puntería. La onomatopeya deriva de que los fusiles, en los barrancos, sonaban haciendo un «pa»y su eco se percibía como «co».

28. Existe una línea de investigación muy potente que se ocupa de estudiar la imagen del marroquí en la memoria colectiva de los españoles mediante el empleo de muy variopintas fuentes (Martín, 2002).

29. ESCORIAZA, Teresa de, «Del dolor de la guerra. Poblado destruido», La Libertad, 24 de septiembre de 1921, p. 1. 
cuna volcada, símbolo de una familia destruida al completo. Es curioso, pero en lo que atañía a la población civil, Teresa no marcaba fronteras entre españoles y rifeños. Para ella todos eran víctimas de la barbarie ya que todos arrastrarían heridas permanentemente.

Junto a estos dos escenarios, en este corpus de crónicas es posible localizar también tres espacios donde reina el pesimismo de la soldadesca y se lleva al límite su capacidad de resistencia (lo que enlaza con el estereotipo sobre la dureza del combatiente peninsular): para empezar, en los blocaos. Teresa visitó uno de ellos y no tardó en retratar -casi con nitidez fotográfica- a sus moradores:

«Hacinados en el estrecho recinto, sin poder asomarse a respirar aire más puro del que allí se condensa, a riesgo de recibir la bala de alguno de los pacos emboscados en la cañada próxima o en la cresta vecina, pasan el oficial y los soldados las largas, las eternas horas. Los rayos del sol de África, que calcina las paredes, les someten a una temperatura de horno [...] hambreados y sedientos, no tienen ni el consuelo del sueño ${ }^{30}$.

El hambre, la sed y la suciedad no eran los únicos demonios que presidían la vida en el blocao. Teresa añadía, y volvemos sobre esa idea de los sacrificios que impone la patria, el combate nocturno. Se trataba del más habitual en este tipo de fortificaciones defensivas, pero la cronista lo tildaba de innoble. No obstante, sabemos que encajaba de pleno en la lógica del conflicto asimétrico (de acuerdo con la terminología moderna) porque se buscaba el agotamiento psicológico de los españoles al privarlos del sueño. Al final, estos hombres dependían en exclusiva de sus propios medios para subsistir, pues la escasez minaba su moral y el mal estado de los caminos impedía tanto el traslado ágil de suministros como una evacuación rápida ${ }^{31}$.

También mientras se realizaban las aguadas se palpaba la aflicción reinante entre los integrantes del convoy ${ }^{32}$. Escoriaza las describe como acciones peligrosas, hechas en absoluto silencio al amanecer. La experiencia resultaba un «tormento atroz» para el soldado peninsular, atento a cualquier sonido que pudiese descubrir a un embocado rifeño y, por ello, la periodista elogiaba -una actuación constante, por otra parte- su valentía.

30. ESCORIAZA, Teresa de, «Del dolor de la guerra. La tristeza del blocao», La Libertad, 13 de septiembre de 1921, pp. 1-2.

31. Silvestre, por ejemplo, solicitó créditos a Berenguer para la construcción de caminos en numerosas ocasiones. Documentos referentes acerca del suplicatorio pidiendo autorización para procesar al señor senador don Dámaso Berenguer, Diario de Sesiones de Cortes, Senado, Apéndice extraordinario al n ${ }^{\circ}$ 94, 1 de diciembre de 1922, pp. 4-5.

32. ESCORIAZA, Teresa de, «Del dolor de la guerra. Sale el convoy», La Libertad, 25 de septiembre de 1921, p. 1. 
Por último, el tercer escenario que apuntala ese tono melancólico de las crónicas es el del buque-hospital Alicante: un transatlántico de lujo, reaprovechado con fines humanitarios, y que Teresa recorre gracias a la amabilidad de su capitán, Agustín Gibernau. Tras charlar con algunos convalecientes, la joven cronista extrae una lección crucial, la de que ellos no sienten consuelo por regresar a sus hogares para curarse, sino que lo que desean en retomar el combate cuanto antes: «En todo herido hay un vencido siempre [...] A él le han pegado y quiere, pegando, desquitarse ${ }^{33}$. Es el clásico ojo por ojo con toda su crudeza y que Teresa convierte en un deseo falsamente compartido por todos los expedicionarios. El anhelo por regresar al hogar pesaba y lo hacía más, como parece lógico, entre la tropa de leva que entre la oficialidad.

Si bien es imposible cuantificar el peso de ese deseo de desquite, y lo mismo ocurre con otra emoción como la nostalgia, sí es constatable cómo en el discurso periodístico inmediatamente posterior a Annual dominó el Talión. Las crónicas de Escoriaza, desde luego, no fueron la excepción porque el efecto Rally Round the Flag, la política de la visceralidad fruto del desastre, funcionaba a toda máquina. Esa mirada compasiva-ignoremos si impostada o sincera-ante la destrucción que presencia en Nador, con todo, sí alejó algo a Escoriaza de los argumentos hegemónicos en los rotativos del momento.

\section{El Ejército de África, quintaesencia de la camaradería, la obediencia y el heroísmo}

En las crónicas de Teresa coexisten, paradójicamente, la denuncia permanente del dolor de la guerra y las peticiones de venganza. La revancha, esa incubadora de odio contra el moro, se convirtió además en la gran obsesión y motor del ejército expedicionario, y de toda España por extensión -o casi-, hasta el término de 1921 cuando el agotamiento ante el goteo de bajas en combate y la impaciencia generada por el proceso responsabilista, por el regreso de los «cuotas» y por el anhelado rescate de los prisioneros animaron a las masas a tomar las calles con brío para protestar por la prolongación de la guerra (Gajate, 2019: 100-102). Insistamos en que solo entonces la prensa empezó a evidenciar más discrepancias a la hora de sostener la llama de la venganza. Por el momento, en circunstancias tan duras para los combatientes, lejos de sus hogares y enfrentados a un correoso enemigo, la camaradería adquirió una relevancia desproporcionada y acaparó, naturalmente, la atención de Escoriaza, sobrada de olfato periodístico. Pero, ¿qué otros rasgos definen al ejército que

33. ESCORIAZA, Teresa de, «Del dolor de la guerra. Pasaje ensangrentado», La Libertad, 9 de septiembre de 1921, p. 1. 
conoció Teresa? De la lectura de la serie «Del dolor de la guerra» se extrae, por una parte, la imagen de un ejército dual y, por otra, la de un ejército heroico.

En lo que atañe a esa dualidad, la producción historiográfica sobre las fuerzas armadas en tiempos del monarca Alfonso XIII es, como la referida a Annual, muy abundante y ha insistido en la idea de las fracturas castrenses, germen de la posterior y trágica división de 1936 (Cardona, 1983; Alía, 2018; Losada, 2020): cuerpos técnicos (Ingenieros y Estado Mayor) contra armas generales (Infantería y Caballería); junteros contra africanistas (Iglesias, 2016); e, incluso, dentro de esta última familia, «berengueristas» contra «manolos» ${ }^{34}$. Teresa, sin embargo, mostró otra división del todo innegable, y quizás por ello -por ser tan evidente- más desatendida en el ámbito académico, pero con notable utilidad propagandística. Nos referimos al contraste entre la oficialidad y la tropa.

El trato relajado entre unos y otros se convirtió, o así lo quiso creer ella, en una garantía de éxito en el campo de batalla. Porque era una de las claves -al igual que el dominio tecnológico o el conocimiento certero de la topografíapara el sostenimiento de la tan necesaria alta moral de combate. Es a la hora de transmitir esta idea (una estereotipada camaradería) donde aparece la Teresa más apasionada, la convencida de la superioridad de las armas españolas y de la idoneidad del proyecto colonial peninsular. Entre los oficiales, se hallan algunas referencias a González Tablas y, en menor medida, a José Millán Astray. Del afamado teniente coronel de los Regulares de Ceuta, Teresa refiere un episodio cuando varios legionarios, de esos que «no temen ni al diablo ni a Dios», se disponían a saquear un poblado aparentemente abandonado ${ }^{35}$. Se toparon, en realidad, con una emboscada y tuvieron que refugiarse en un silo. Desde un lugar próximo, González Tablas decidió auxiliarlos, enviando a un grupo de voluntarios dirigidos por un cabo agradecido. Agradecido, sí, pese a que su misión era suicida, por ser el «elegido» de su superior. Quedaba de este modo patente la importancia de la disciplina y la bravura ${ }^{36}$.

34. Ambos vocablos aluden a la diferencia de criterios, en el periodo 1919-1921, entre los experimentados generales Dámaso Berenguer y Manuel Fernández Silvestre. El primero era partidario de un avance político, con socorro militar, mientras que Silvestre se decantaba con la conquista a viva fuerza.

35. ESCORIAZA, Teresa de, «Del dolor de la guerra. Jefe herido», La Libertad, 14 de septiembre de 1921, p. 1.

36. Los valores de la Legión (camaradería, sacrificio, nacionalismo español a ultranza, antibolchevismo y rechazo hacia el turnismo) se convirtieron en el ADN de los militares africanistas. Además, el legionario encarnó un modelo de masculinidad que, curiosamente, se nutría de la imagen que poseían del combatiente rifeño, caracterizada sobre todo por la exaltación de la violencia y el fanatismo (Bolorinos, 2017: 122). 
En otra crónica, Teresa de Escoriaza describió un ridículo encontronazo entre Millán Astray, presentado como un jefe valiente y juicioso, y los responsables de La Libertad por permitir que ella se ubicase en la primera línea de frente. Ortega y Oteyza se amilanaron con sus palabras, mientras que Teresa optó por aceptar la reprimenda: «El bravo jefe de la Legión tiene razón que le sobra: "La guerra es una cosa muy seria". Y no lo es solo para él tan consciente de su responsabilidad. Lo es para todos sin excepción ninguna. ¡También para los que bromean ante el peligro! $\aleph^{37}$. En suma, ella acapara todo el protagonismo de la acción -no deja de constituir una hábil técnica narrativa de persuasión-y de paso, una vez más, aplaude el buen hacer del mando.

La tropa, por su parte, presume de leal y de capacidad de sacrificio (más estereotipos sobre los expedicionarios peninsulares). Pero no de cultura ${ }^{38}$. Teresa muestra dos ejemplos de su inconsistencia, de la más pura ignorancia acerca de sus circunstancias. El primero, es el caso de un alférez que propone al encararse con unos moros "cargárnoslos amistosamente», lo que bien revela cómo se entiende la labor de protectorado; y el otro, bastante cómico, nos revela nuevamente a un alférez que, presumiendo de que ha aprendido árabe en un mes, es llamado a una entrevista por el mismísimo Beigdeber: «Se encuentra con que no sabe decir ni jamalajá. Pero ¿qué diablos de árabe sabe usted?». A la pregunta colérica contesta pacíficamente el interrogado que sabe decir: ¿Guere güivos?, pimientos mocho grandes, güenas mujeras, etc. ¡El árabe vulgar! El árabe vulgarísimo que hablan los moros vendedores ambulantes que visitan la plaza» ${ }^{39}$. La lacra del analfabetismo no entendía de fronteras y, en tal circunstancia, parecía difícil contemplar al soldado español como un agente civilizador.

De este contraste se derivaba, no obstante, el absoluto protagonismo de la oficialidad en los momentos más críticos. Teresa quería salvaguardar, y aquí reside la otra pieza clave de sus impresiones sobre los africanistas, la fe en un ejército heroico: «Al jefe sereno, al jefe valeroso, al jefe heroico, sus soldados le veneran y le adoran ${ }^{40}$. Se trata de una imagen controvertida, un estereotipo con notable carga propagandística y predicamento, sobre todo, entre la opi-

37. ESCORIAZA, Teresa de, «Del dolor de la guerra. Alegría trágica», La Libertad, 11 de septiembre de 1921, p. 1.

38. El analfabetismo era común entre la tropa, pero debe hacerse hincapié en el papel alfabetizador desempeñado conscientemente por el ejército en la edad contemporánea (Quiroga del Valle, 1999).

39. ESCORIAZA, Teresa de, «Del dolor de la guerra. Alegría trágica», La Libertad, 11 de septiembre de 1921, p. 1

40. ESCORIAZA, Teresa de, «Del dolor de la guerra. Jefe herido», La Libertad, 14 de septiembre de 1921, p. 1. 
nión ultranacionalista y vocinglera. Sin embargo, en Marruecos se cometieron demasiados abusos por parte de los oficiales y ello contribuyó a explicar las deserciones indígenas durante la debacle de julio (Albi, 2014: 99). Annual había terminado por desbaratar la confianza hasta entonces depositada en los soldados indígenas como fuerza de choque, pues sus defecciones fueron una de las causas del desorden que se impuso en las operaciones de retirada de 1921 (Villalobos, 2004: 131-134). Esta realidad es aquí no solo silenciada, sino que Teresa utiliza el ejemplo de un combatiente de Beni Sidel para mostrar todo lo contrario. Cuando su madre, y hasta el propio José Riquelme, lo presionan para que retorne a su hogar, lo rechaza tozudamente y se queda con su «patria de adopción $»^{41}$. Es el ejemplo de la lealtad en grado sumo.

Siguiendo con el análisis de las tropas de choque, particularmente llamativo es el caso de los legionarios, individuos sobrados de fanfarronería cuyo sustento fue -y así lo subraya machaconamente la reportera- el más visceral sentimiento de odio. Teresa ilustraba esta idea relatando el caso de un joven despechado, que después de que su novia lo abandone, decide alistarse en el Tercio. Su experiencia es traumática porque «resulta un infeliz a quien abruman las fatigas y no sirve para los riegos [...] Si fuese como sus compañeros, los que hieren sin duelo, los que razzian (sic) sin conciencia, los que caen sin dolor, tendría elogios y premios $»^{42}$. De nuevo, brutalidad, camaradería, revancha y más revancha. Autores como Dionisio Viscarri, de hecho, han asociado ese empeño en la política del desquite directamente con el nacimiento del fascismo en España. Según este investigador (2004: 55), Annual significó el nacimiento de una nueva milicia:

«Un ejército colonial brutalizado y endurecido, sin límites de comportamiento. Marroquíes y españoles hicieron la guerra total. Mutilaciones, violaciones y otras crueldades inimaginables, formaron parte de la conducta habitual de los combatientes. El deseo de venganza tras la carnicería de Annual fue el gran motivador de la contraofensiva española, pero sirvió para justificar los peores excesos y represalias».

Puesto que el contingente de legionarios no resultaba suficiente y los quintos tenían un grado de instrucción solo equiparable a su pésima motivación -comprensible, por otra parte-, se legitimaban los métodos alternativos de combate: las mencionadas columnas móviles, los bombardeos y las armas químicas (Madariaga; Lázaro, 2003).

41. ESCORIAZA, Teresa de, «Del dolor de la guerra. La tragedia de los regulares», $L a$ Libertad, 7 de septiembre de 1921, p. 1.

42. ESCORIAZA, Teresa de, «Del dolor de la guerra. Legionario por amor», La Libertad, 22 de septiembre de 1921, p. 1. 


\section{Emociones a flor de piel: Teresa de Escoriaza y la moral legionaria}

El sostenimiento de una elevada moral de combate se convirtió en la piedra angular para que cada cual desempeñase correctamente su tarea en África. Por este motivo, junto a la negación de las deserciones y la exaltación de la disciplina, los instrumentos de Teresa de Escoriaza para lograr ese imprescindible elevado espíritu de lucha fueron las llamadas directas a la guerra-denunciando, recuérdese, la inactividad en Melilla o aplaudiendo su marcha al frente $e^{43}-y$, mucho más original, reconociendo el papel desempeñado por la correspondencia privada en el sostenimiento del ánimo belicoso. No debe perderse de vista que Teresa escribía por y para las mujeres. Ellas eran las que enviaban (de su puño y letra o, las más de las veces, con ayuda) centenares de cartas que aplacaban los nervios de sus hijos, hermanos, novios... ellas, por tanto, merecían el elogio de la cronista. Y así lo reconocía cuando, tras una celada mora sobre un vehículo blindado, quedaron dispersas centenares de cartas por el camino. ¿Qué había en ellas? Teresa creía que un «bálsamo para las heridas, alivio para la enfermedad» ${ }^{44}$. Y concluía, en tono lapidario: «Alguna de esas cartas, al perderse, pudo dejar sin hacer un héroe y ha podido hacer un mártir».

La explotación de la sensibilidad popular, desde luego, estuvo muy presente en los escritos de Escoriaza. Presumió, por ejemplo, de cumplir un encargo de una suscriptora de La Libertad al contactar con su hijo para comprobar que se hallaba bien en Marruecos ${ }^{45}$. Pero fue más allá al instrumentalizar dos asuntos tan espinosos como el rescate de los prisioneros y la muerte. La cautividad en territorio rifeño constituía, en efecto, la pesadilla de miles de españoles, temerosos de las vejaciones (insultos, malos tratos y hambre). Así las cosas, la vasca ponía en boca de la esposa de un apresado por Abd-el-Krim este comentario: «Es peor que si estuviese herido... ¡Peor que si hubiese muerto! $»^{46}$. A pesar de los múltiples intentos de mediación con el caudillo rifeño, el rescate no fue posible hasta enero de 1923. Es decir, dieciocho meses después de la masacre de Annual. El entonces ministro de Estado, Santiago Alba, hubo de confiar oficialmente a Horacio Echevarrieta las gestiones para el rescate. Llegó este empresario a la bahía de Alhucemas el 24 de enero de 1923 y en menos de una

43. ESCORIAZA, Teresa de, «Del dolor de la guerra. Morituri te salutam», La Libertad, 8 de septiembre de 1921, p. 1. En concreto, aquí se da cuenta de la despedida que Melilla dispensa a las fuerzas del regimiento de Borbón.

44. ESCORIAZA, Teresa de, «Del dolor de la guerra. Cartas perdidas», La Libertad, 15 de septiembre de 1921, p. 1.

45. ESCORIAZA, Teresa de, «Del dolor de la guerra. Angustia maternal», La Libertad, 18 de septiembre de 1921, p. 1.

46. ESCORIAZA, Teresa de, «Del dolor de la guerra. La esposa del cautivo», La Libertad, 4 de septiembre de 1921, p. 2. 
semana, previo desembolso de cuatro millones de pesetas, logró la liberación de los 367 cautivos supervivientes (Ramiro, 2002).

La muerte, más allá del mecánico recuento de bajas, también copó la atención de Escoriaza. No sorprende, por tanto, que llorara y exteriorizara su desconsuelo coincidiendo con el fallecimiento de un soldado al que conocía ${ }^{47}$; o que protestara por la falta de humanidad en el traslado de cadáveres, cuando los vio apilados bajo la lona de un camión ${ }^{48}$. Sin embargo, y reparemos en otra peculiaridad del discurso de Teresa, ocasionalmente la muerte era una liberación para el vencido. Por este motivo se compadeció de un oficial que intentó quitarse la vida tras resultar ileso en una calamitosa operación de retirada ${ }^{49}$. La reportera no aprobaba semejante conducta, aunque entendiese su «tortura». Su intención, al contrario, era denunciar el suicidio como remedio ante el amilanamiento. En cualquier caso, admitir estos gestos cobardes, así como reconocer esas oscuras prácticas no fue habitual, desde luego, entre los enviados que cubrieron la guerra del Rif y constituyó uno de los apuntes más originales en la obra de Escoriaza ${ }^{50}$.

Bajas en combate, poblados hechos cenizas, razias, celadas sobre vehículos, infinidad de noches de insomnio, etc. se sucedían en la violentísima contienda del Rif. Escoriaza abordó todos estos asuntos, sensibilizándose con las víctimas civiles -con independencia del bando al que perteneciesen-y, en particular, con las víctimas de violación y con los huérfanos. Así las cosas, Teresa de Escoriaza relató, y a la par clamó venganza una vez más, la violación de una jovencita de diecisiete años. No aclaraba que se tratase de una rifeña, si bien se deduce por la alusión a su apresamiento en un poblado y a que tenía parientes en un aduar próximo a Melilla: «La enviaron de una cabila a otra, como si deseasen que todo el Rif saciase en ella su barbarie» ${ }^{51}$. Terminaron por mutilarle los pechos y la entregaron en el Atalayón, donde falleció poco después. El colaboracionismo con los españoles se pagaba caro, tal y como se colige de la lectura. El varón rifeño, añádase, era descrito como un salvaje más si cabe con sus correligionarios.

47. ESCORIAZA, Teresa de, «Del dolor de la guerra. El amigo que cae», La Libertad, 10 de septiembre de 1921, p. 1.

48. ESCORIAZA, Teresa de, «Del dolor de la guerra. El camión de los muertos», La Libertad, 21 de septiembre de 1921, p. 1.

49. ESCORIAZA, Teresa de, «Del dolor de la guerra. La desdicha del vencido», La Libertad, 20 de septiembre de 1921, p. 1.

50. La historiografía actual sí ha reparado en este turbio asunto restándole importancia numérica (Gudín, 2012).

51. ESCORIAZA, Teresa de, «Del dolor de la guerra. Barbarie inaudita», La Libertad, 16 de septiembre de 1921, p. 1. 
En otra ocasión, la periodista vio como la Cruz Roja rescató a un niño morito, de unos cinco años, que había perdido a su madre en una explosión. Su conclusión resultaba aplastante: «A medida que el tiempo pase el recuerdo que ahora le atormenta se desarrollará para atormentarle todavía más $»^{52}$. Es decir, de la guerra solo germinaban sentimientos malos y heridas imposibles de cicatrizar. A Teresa, en definitiva, le inquietaba el futuro de la región al tiempo que asumía la imposibilidad de una labor protectora hasta entonces.

\section{Conclusiones}

Teresa de Escoriaza fue una luchadora tanto en lo personal como en lo laboral y una pionera del reporterismo bélico, un oficio tradicionalmente dominado por los hombres. Además, no lo olvidemos, su modo de entender la lucha feminista también rompió moldes. Su carácter aventurero aflora cuando aprende idiomas, viaja al extranjero y, particularmente, al desenvolverse como cronista de guerra en el Rif. Al igual que hicieron muchos otros periodistas y medios de comunicación, Teresa sucumbió ante el pánico imperante en el verano de 1921. Lo cierto fue que solo algunas publicaciones, muy pocas y con una clara vocación antisistema, como pudiera ser El Socialista, se mantuvieron ya desde el verano en alerta -reclamando el necesario esclarecimiento de responsabilidades- para, de modo paulatino y coincidiendo con la reapertura de las Cortes a finales de octubre de 1921, endurecer su discurso opositor (Moreno, 1990: 108). Teresa de Escoriaza, con su singular modo de entender el oficio, pidió venganza a la par que reconoció la barbarie de la contienda y la sangría que suponía. Un absurdo, probablemente fruto de cierto debate interno, que se resolvió lamentando desde la honestidad las secuelas de la guerra: la inoperancia del Protectorado.

En las crónicas de Escoriaza, sin embargo, no encontramos culpables, ni políticos -jamás menciona a Maura, La Cierva, etc.- ni militares, sino héroes. Esquivando el espinoso asunto de las responsabilidades de Annual, pero omitiendo también las machaconas alusiones al honor de España, Teresa pudo granjearse la simpatía del núcleo duro del africanismo (oficiales de los Regulares y la Legión). Su público predilecto fue, no obstante, el femenino y pudo seducirlo gracias a esa mirada tierna hacia las víctimas y a la denuncia de su dolor. Las crónicas de esta periodista, por tanto, sirvieron como amplificadoras de algunos postulados africanistas entre las mujeres. Escoriaza recorrió el teatro de la campaña del Rif, se desvivió en atenciones hacia los jóvenes

52. ESCORIAZA, Teresa de, «Del dolor de la guerra. La semilla fatal», La Libertad, 27 de septiembre de 1921, p. 1. 
soldados peninsulares, aplaudió el comportamiento de las tropas de choque, compadeció a todas las víctimas y no ocultó sus dudas a propósito del incierto futuro del Protectorado. Creemos que la originalidad de su obra reside, en primer lugar, en la idea de la muerte como amenaza a la par que anhelo. En segundo lugar, en sus crónicas se aprecia cómo la incurabilidad del dolor gana protagonismo a medida que avanza septiembre. Ambos elementos ilustran bien el desconcierto que invadió a Teresa de Escoriaza con motivo del desastre de Annual. No hay epopeya, pero sí quedan superhombres.

Annual significó, en definitiva, un gigantesco varapalo para la monarquía de Alfonso XIII, robusteció el tópico de la singularidad histórica española, ahondó en el medio plazo la brecha entre los poderes civil y militar y, por último, acrecentó las tensiones entre las distintas familias del ejército. La rendición de posiciones, a menudo de forma vergonzosa, y los lacrimógenos relatos de los supervivientes removieron los cimientos de la sociedad española. Paradójicamente, el desastre de 1921 -del que se cumple ahora su primer centenario-sirvió para aunar al pueblo, al menos de modo efímero, en la defensa de una guerra cuyas motivaciones muy pocos comprendían. Fue el caso de Teresa de Escoriaza: no le interesaron las causas de la matanza ni los pormenores estratégicos, tampoco contabilizó bajas ni persiguió a los culpables. Prefirió llamar al desquite y aplaudir a sus protagonistas, pero sin lograr silenciar su dolor. Una incongruencia que revelaba, en cierto modo, el papel ambivalente de la prensa al analizar la contienda. Todo ello, creemos, fue el resultado del sinsentido que presenció.

\section{Bibliotecas y Archivos}

Biblioteca Nacional de España, Madrid.

Biblioteca Virtual de Prensa Histórica.

Casa-Museo Miguel de Unamuno, Salamanca.

Archivo Histórico Nacional, Madrid.

Archivo del Senado de España, Madrid.

\section{Bibliografía}

ALÍA MIRANDA, Francisco (2018). Historia del ejército español y de su intervención política. Del desastre del 98 a la Transición. Madrid: Catarata.

ALBI DE LA CUESTA, Julio (2014). En torno a Annual. Madrid: Ministerio de Defensa.

BALFOUR, Sebastian; LA PORTE, Pablo (2000). «Spanish military cultures and the Maroccan wars, 1909-1936». European History Quarterly, 30(3), 307-332. https://doi.org/10.1177/026569140003000302 
BALFOUR, Sebastian (2002). Abrazo mortal. De la guerra colonial a la Guerra Civil en España y Marruecos (1909-1939). Barcelona: Ediciones Península. BASALLO, Francisco (1924). Memorias del cautiverio. Madrid: Mundo Latino.

BAUM, Matthew A.; POTTER, Philip B. K. (2008). «The relationships between mass media, public opinion, and foreign policy: toward a theoretical synthesis». Annual Review of Political Science,11, 39-65. https://doi.org/10.1146/ annurev.polisci.11.060406.214132

BOLORINOS ALLARD, Elisabeth (2016). «Masculinidad, identidad guerrera y la imagen del Regular marroquí en la propaganda del bando sublevado en la guerra civil española». Norba. Revista de Historia, 29-30, 121-134. http://hdl. handle.net/10662/7548

CABALLERO ECHEVARRÍA, Fernando (2013). Intervencionismo español en Marruecos (1898-1928): análisis de factores que confluyen en un desastre militar, Annual. Tesis doctoral inédita: Universidad Complutense de Madrid.

CARDONA, Gabriel (1983). El poder militar en la España Contemporánea hasta la Guerra Civil. Madrid: Siglo XXI.

CASADO Y ESCUDERO, Luis (2007). Igueriben. Madrid: Ediciones Almena.

COMALADA, Ángel (1985). España: El ocaso de un Parlamento, 1921-1923. Barcelona: Ediciones Península.

DELGADO IDARRETA, José Miguel (2003). «La prensa: fuente historiográfica». En VVAA. Investigación humanística y científica en la Rioja (245-255). La Rioja: Aróspide/Instituto de Estudios Riojanos.

DÍEZ RIOJA, Ramón (2019). El desembarco de Alhucemas. La operación definitiva del colonialismo español en Marruecos (1911-1925). Tesis doctoral inédita: Universidad Autónoma de Madrid.

FRANCISCO, Luis Miguel (2014). Morir en África. La epopeya de los soldados españoles en el Desastre de Annual. Barcelona: Crítica.

FUENTES, Juan Francisco; FERNÁNDEZ SEBASTIÁN, Javier (1997). Historia del periodismo español: prensa, política y opinión pública en la España contemporánea. Madrid: Síntesis.

GAJATE BAJO, María (2012). Las campañas de Marruecos y la opinión pública. El ejemplo de Salamanca y su prensa (1906-1927). Madrid: IUGM.

GARCÍA PALOMARES, Antonio (2014). El origen del periodismo de guerra actual en España: el análisis de los corresponsales en el conflicto del Norte de África entre 1893 y 1925. Tesis doctoral inédita: Universidad Complutense de Madrid.

GÓMEZ HIDALGO, Francisco (1921). La tragedia prevista. Madrid: Imprenta de Juan Pueyo.

GÓMEZ MARTÍNEZ, Juan Antonio (2009). «La actuación del general Fernández Silvestre al mando de la Comandancia General de Melilla y su responsabilidad en el desastre de Annual». Aportes. Revista de Historia Contemporánea. 71(3), 50-107. 
GROELING, Tim; BAUM, Matthew A. (2008). Crossing the Water's Edge: Elite rhetoric, media coverage, and rally-round-the-flag phenomenon. The Journal of Politics. 70(4), 1065-1085. https://doi.org/10.1017/S0022381608081061

GUDÍN DE LA LAMA, Enrique (2012). Un mito convertido en tópico: los suicidios en el ejército en los días de Annual. Revista de Historia Militar, 112, 229-264.

IGLESIAS AMORÍN, Alfonso (2016). La cultura africanista en el ejército español (1909-1975). Pasado y memoria. Revista de Historia Contemporánea. 15, 99-122. https://doi.org/10.14198/PASADO2016.15.04

LA PORTE, Pablo (1997). El Desastre de Annual y la crisis de la Restauración en España (1921-1923). Tesis doctoral inédita: Universidad Complutense de Madrid.

LA PORTE, Pablo (2001). La atracción del imán. El Desastre de Annual y sus repercusiones en la política europea (1921-1923). Madrid: Biblioteca Nueva.

LEGUINECHE, Manuel (1996). Annual, 1921. El desastre de España en el Rif. Madrid: Alfaguara.

LOPEZ ALCÓN, Noemí (2015). La narrativa breve y la crónica de guerra (19001945). Estudio interdiscusivo y comparado. Tesis doctoral inédita: Universidad de Murcia.

LOSADA, Juan Carlos (2020). El ogro patriótico. Los militares contra el pueblo en la España del siglo XX. Barcelona: Pasado y Presente.

MACÍAS FERNÁNDEZ, Daniel (2019). Franco «nació en África»: los africanistas y las campañas de Marruecos. Madrid: Tecnos.

MADARIAGA, M. ${ }^{a}$ Rosa de; LÁZARO ÁVILA, Carlos (2003). Guerra química en el Rif. Historia, 324,50-87.

MADARIAGA, M. ${ }^{a}$ Rosa de (2005). En el Barranco del Lobo. Las guerras de Marruecos. Madrid: Alianza Editorial.

MADARIAGA, M. ${ }^{a}$ Rosa de (2009). Abd-el-Krim El Jatabi. La lucha por la independencia, Madrid: Alianza Editorial.

MARICHALAR, Luis de (1923). Mi responsabilidad en el Desastre de Melilla como ministro de la Guerra. Madrid: Gráficas Reunidas.

MARÍN, Manuela (2013). «Colonialismo, género y periodismo. Cuatro mujeres españolas en las guerras con Marruecos (1909-1927)». Clepsydra: Revista de Estudios de Género y Teoría Feminista. 12, 11-42. http://riull.ull.es/xmlui/ handle/915/2286

MARTÍN CORRALES, Eloy (2002). La imagen del magrebí en España. Una perspectiva histórica: siglo XVI-XX. Barcelona: Ministerio de Educación, Cultura y Deportes.

MARTÍNEZ GALLEGO, Francesc-Andreu, LAGUNA PLATERO, Antonio (2014). Comunicación, propaganda y censura en la guerra hispano-marroquí (1906-1925). Comunicación y Sociedad, 27(3), 43-63. http://hdl.handle. net/10578/3838 
MARTÍNEZ CARRERAS, José U. (2000). España y Marruecos a comienzos del siglo XX. En José U. MARTÍNEZ CARRERAS (Coord.). Relaciones entre España y Marruecos en el siglo XX (9-21). Madrid: Asociación Española de Africanistas. MOGA ROMERO, Víctor (2004). El soldado occidental. Ramón J. Sender en África (1923-1924). Málaga: UNED/Ciudad Autónoma de Melilla.

MORENO JUSTE, Antonio (1990). El Socialista y el desastre de Annual: opinión y actitud socialista ante la derrota. Cuadernos de Historia Contemporánea, 12, 103-132.

NÚÑEZ REY, Concepción (1991). Carmen de Burgos «Colombine» (1867-1932). Biografía y obra literaria. Tesis doctoral inédita: Universidad Complutense de Madrid.

ORTEGA Y GASSET, Eduardo (1922). Annual: Relato de un soldado e impresiones de un cronista. Madrid: Rivadeneyra.

OTEYZA, Luis (2000). Abd-el-Krim y los prisioneros. Melilla: Consejería de Cultura. PABÓN, Jesús (1952). Cambó. Barcelona: Editorial Alpha.

PALENQUE, Marta (2006). Ni Ofelias ni amazonas, sino seres completos: aproximación a Teresa de Escoriaza. Arbor. Ciencia, pensamiento y cultura, 719, 363-376. https://doi.org/10.3989/arbor.2006.i719.36

PANDO DESPIERTO, Juan (1999). Historia secreta de Annual. Madrid: Temas de Hoy.

PENNELL, Richard C. (2001). La Guerra del Rif. Abd-el-Krim el-Jattabi y su estado rifeño. Melilla: Biblioteca de Melilla.

PÉREZ ORTIZ, Eduardo (1923). 18 meses de cautiverio. De Annual a Monte Arruit (Crónica de un testigo). Melilla: Artes Gráficas Postal Express.

PRIETO, Indalecio (1990). Con el Rey o contra el Rey: la guerra de Marruecos (2 vols.). Barcelona: Planeta.

PRIETO, Indalecio (2001). Crónicas de guerra. Melilla, 1921. Málaga: Algazara.

QUIROGA VALLE, María Gloria (1999). El papel alfabetizador del Ejército de Tierra español (1893-1954). Madrid: Ministerio de Defensa.

RAMIRO DE LA MATA, Javier (2001). Origen y dinámica del colonialismo español en Marruecos. Ceuta: Archivo Central.

RAMIRO DE LA MATA, Javier (2002). Los prisioneros españoles cautivos de Abdel-Krim: un legado del Desastre de Annual. Anales de Historia Contemporánea, 18, 341-353.

RUBIO CAMPAÑA, Antonio (2005). Periodistas españoles en la Guerra del Rif (Marruecos): 1921-1923. Origen del periodismo de investigación en España. Tesis doctoral inédita: Universidad Autónoma de Madrid.

RUBIO CAMPAÑA, Antonio (2015). Luis de Oteyza o el oficio de investigar. Madrid: Libros.com. 
RUIZ ALBÉNIZ, Víctor (1922). Ecce Homo. Prueba documental y aportes inéditos sobre las causas del derrumbamiento y consecuencias de él. Madrid: Biblioteca Nueva.

SEOANE, María Cruz; SÁIZ, Dolores (1996). Historia del periodismo en España. El siglo XX: 1898-1936. Volumen 3. Madrid: Alianza Editorial.

SERNA, Alfonso de la (2001). Al sur de Tarifa: España-Marruecos, un malentendido histórico. Madrid: Marcial Pons.

TERREROS CEBALLOS, Gonzalo (2013). Antonio Maura y la cuestión marroquí. Tesis doctoral inédita: Universidad Complutense de Madrid.

VILLALOBOS, Federico (2004). El sueño colonial. Las guerras de España en Marruecos. Barcelona: Ariel.

VILLANOVA VALERO, José Luis (2005). La pugna entre militares y civiles por el control de la actividad interventora en el protectorado español en Marruecos (1912-1956). Hispania, 220, 683-716. https://doi.org/10.3989/hispania.2005. v65.i220.146

VISCARRI, Dionisio (2004). Nacionalismo autoritario y orientalismo. La narrativa prefascista de la guerra de Marruecos (1921-1927). Bolonia: Il Capitello del Sole. VIVERO, Augusto (1922). El derrumbamiento. La verdad sobre el desastre del Rif. Madrid: Caro Raggio.

WOOLMAN, David S. (1971). Abd-el-Krim y la guerra del Rif. Barcelona: Biblioteca Tau.

ZAPATA-CALLE, Ana (2011). En la guerra de Carmen de Burgos Crítica del proceso de nacionalización e imperialismo español en Marruecos, Decimonónica, 8(2), 91-110. 